\title{
The culture of disability: A social expose`
}

\author{
Book Review \\ Serena Mullins
}

\author{
Planet of the Blind \\ By Stephen Kuusisto \\ Faber \& Faber (1998) 194pp.
}

Planet of the Blind, an autobiographical work and the first of Kuusisto's literary collection, gives a full and frank description of growing up blind in the 1950s and 60s in America, before the advent of disability rights and activism. Kuusisto covers all the topics you would expect in a memoir, however through a lens of disablement that shaped and coloured a significant part of his early adult life. The style of writing is both explanatory and poetic and while the reader is invited on the journey, it is clear that Kuusisto seeks absolution and atonement for past mistakes and transgressions. Themes of empowerment are universally affecting however and it is no less so in Kuusisto's case, as we embrace his potential and hope for the future. Ultimately the search for identity, belonging and acceptance is something that touches us all; across both the humanness of fallibility and experiences of mutual exchange and reciprocity. Therefore, while the memoir has singular reward for Kuusisto, he gifts the message that pretence and fabrication has the potential to erode personal and social conscience.

\section{Truth in self-expression}

In analysing an autobiography we are effectively evaluating someone's truth, surely relative to individual experience. The psychiatrist and philosopher Jung (1963) in his memoir talks about the legitimacy of narrative and through the simplicity of his statement "my fable, my truth" (p. 17), expresses the understanding that all stories have equal weight and integrity. The stark profundity of Kuusisto's tale is that it travels across times and history and showcases schools of disability thought and perception. From past eras, the reader glimpses the vivid reality of being blind. This single word conjures up a wealth of image and while replaced in contemporary society by more subtle nuances of 'vision impaired', Kuusisto allows us to see the full impact of blindness in an era in which disability equated to deficit and affliction. Through an inescapable truth that offers no hope of improvement or remedy we enter the Planet of the Blind.

\section{A childhood journey}

As Kuusisto was born in the mid-50s, the era shaped not only his personal experiences and account, but ultimately bore responsibility for his blindness. Babies 
Planet of the Blind: book review

born prematurely as Kuusisto was at that time were routinely over-oxygenated resulting in blindness from damage to poorly developed retinas. While he grew up in a non-disabled home, he was unable to identify with worlds of either the disabled or non-disabled and often sought comfort with imagination and pretence. He attributes these periods of escapism to his development as a writer and reminisces: "I learnt early how to spin a lone story in a sheltered place" (Kuusisto, 2004, p. 63). Prolonged experiences of solitude and introspection would be oft-repeated, until finally, he was able to move beyond his self-imposed construct, formulated by the retrospective understanding of being "a blind man in a charade" (Kuusisto, 1998, p. 103).

Ever-present in his childhood are the jarring effects of separation and his keen sense of displacement both from self and community. While reflective of an era that offered limited disability supports, the issues and circumstance that Kuusisto recounts and the juxtaposition of competing family and social demands, is no less relevant in contemporary society. This is particularly noteworthy in light of Kuusisto's early appreciation and awareness of difference, which led him to challenge and defy physical space by 'hurtling' through it. His mother meanwhile, with a clearer understanding of the confines and controls imposed through demarcation, attends to his 'inclusive' education with tenacity. While he gained entry to the non-disabled world, he was more than aware that it was a position occupied by default, with which he had insufficient skills and capacities to compete. Therefore while his mother fought for his inclusion, tools to enable this were disavowed. The social myth of disability and docility as mutually compatible was unwittingly propagated, as the context and constrictions associated with the era proved a dominant and insurmountable barrier. Phenomenological expression through the use of a white cane was disallowed, however irrespective, his blindness became its own state; and visibility was never more apparent without specific need of apparatus or announcement.

\section{Adolescence}

In early childhood the challenge of defying space and movement was sufficient to hold self-doubts at bay, however as he grew, he could never quite outrun his blindness. When Kuusisto enters adolescence we see the ways in which he attempts to maintain a sense of control, through the enactment of Foucault's social regulation theories of "supervision" and "surveillance" (Hughes, 2005, p. 90), used as tools for personal subjugation through dietary regimes of binging, obesity and anorexia. In this period he denounces not only his disability but effectively himself. An attempt to mediate and redress his state of blindness through self-injurious behaviour is understood in the work of Jung (1963), that "everything in the unconscious seeks outward manifestation" (p. 17).

\section{Adulthood and lessons learned}

In adulthood Kuusisto's life is marked by inertia. Clarity comes with the realization that his abilities are impinged by his refusal to help himself and not at the whim of impairment, expressed by the singular realization that without a white cane he is nothing. This statement embodies transformative power to contest imprints of stigma imposed on the psyche. Exposure to the world after years of attempting to pass brings its own challenges, often through the vehemence and opinion of others. In the past Kuusisto would have accounted for himself in terms of failings and deficit, now rather, uses opportunities to educate and inform. After receiving his guide dog he 
Planet of the Blind: book review

speaks of a street encounter in which he corrects the misconception that the guide dog is 'leading the experience'. This is a significant life-metaphor: the guide dog has gifted him freedom of expression, however it is only through his will and motivation that he has the power to harness and embrace it.

\section{The way forward}

While Kuusisto has reached and made some life-changing decisions it is clear that his journey continues to evolve. Previous challenges with which he asserted himself through unhealthy lifestyle choices have tempered; and we see him embrace opportunities and exchanges that are possible through the acquisition of his guide dog. Dimensions of the struggle to belong are forefront-represented through the status of visibility; and it is paradoxically through such complete exposure that he finds inclusion and acceptance, regardless of the substance of the exchange. Misconceptions of disability and modern day conversation may resonate similar to those from his youth; however he is now able to respond from a place of self-belief and assertion. It is within these moments signified by his openness and forthrightness he has truly escaped from Foucault's contention of an "inexorable disciplinary regime" (McNay as cited in Hughes, 2005, p. 89), which both instructs and influences us.

\section{Kuusisto accounts for blindness in an era of competing influences of disability and virtue}

The situations and lifestyle his mother wished for him growing up and her struggle to avoid label and stigma was to a large degree stymied by the response and capacities of the era. Irrespective of inclusive settings and 'freed' from authoritarian dictate, Kuusisto's identity was still effectively reduced to a singular disability composite. Unfortunately, while Kuusisto's identity and beliefs changed and adapted, his mother's did not and indeed they became more resolute and fixed. It is while embracing his identity and blindness that Kuusisto finds the tools for emancipation, a pivotal and cathartic moment representing a spiritual awakening, which for his mother, signifies the most ultimate of disclosures. Kuusisto (1998) speaks of the competing influences of disability and virtue and caricatures of "good or ill" (p. 125). For his mother, his impairment was a 'condition' which she failed to correct; and subsequently no inducement is sufficient to allow her to rejoice in his success.

\section{Authentic truth}

Kuusisto openly discusses methodologies of displacement and it is through this, that in addition to an intimate and personal journey, the memoir has validity as a social expose' and commentary. Kuusisto's account invites reflection on the circumstances and constructs which inhibit us and upholds the value of authentic truth as cornerstone within processes of self-discovery and awareness. The significance of this is shown through Kuusisto's ability to let people live their own truth, irrespective of belief or accuracy; and as he remarks "I have to let them go" (Kuusisto, 1998, p. 191). With wisdom and maturity he ended his punishing regime and exile, which allowed the responses of others to be less affecting; and overall, gained the understanding that the only truth we account for is our own.

The memoir does invite us to reflect on a social discourse and conversations of disability that have remained relatively fixed, irrespective of the uniqueness of individual circumstance, situation and era. While legitimacy has to some degree been afforded by legislative policy, it is questionable whether practice matches 
Planet of the Blind: book review

absolute expectation and entitlement. While action keeps us steadfast within ideology and principle, it is often much later with the benefit of hindsight, that perceptions and understandings are more acute. Even today, Kuusisto remarks on being unsure which decisions in childhood were for the best. However as his mother did accurately perceive, schools remain a segregating power which determine hierarchal categories; and subsequent worth is mirrored within the perpetuation of myths of disability and disablement. Within these expressions the true merit of Kuusisto's memoir becomes clear, as it is a work that prompts and facilitates personal contemplation and deliberation.

Fundamentally we each have the ability to regenerate ourselves, aptly described by processes of delving "past the fatty layers of self-deceit and denial" (Zupan, 2006, p. 5); through which we are gifted with greater acuity. The stages of Kuusisto's life reflect this understanding within the paradoxes of being, with which we garner positions of "enslavement" or "freedom" (Hughes, 2005, p. 89). This appreciation is apparent in Kuusisto's final and cornerstone contention that disapprobation reflected in contemporary fields and attitudes no longer guides his social and moral compass. Later writings by Kuusisto describe the joy in bird song and as he listens to their music, his hard-won sense of entitlement and peace are now illustrative of a journey to be lived rather than merely endured.

\section{References}

Hughes, B. (2005). What can Foucauldian analysis contribute to disability theory? In S. Tremain (Ed.), Foucault and the government of disability (pp. 78-92). USA: The University of Michigan Press.

Jung, C.G. (1963). Memories, dreams, reflections. Great Britain: Collins and Routledge \& Kegan Paul.

Kuusisto, S. (1998). Planet of the blind. Great Britain: Faber \& Faber.

Kuusitso, S. (2004). The twa corbies. Project Muse, 6(1), 61-67.

Zupan, M., \& Swanson, T. (2006).You gonna play? How murderball saved my life. London, Great Britain: Aurum Press Ltd.

\section{Biographical Note}

Serena Mullins is a post-graduate student in Disability Studies, School of Human Services \& Social Work, Griffith University. She will soon graduate from the Masters of Human Services program. 